\title{
Monográficos y números especiales en revistas científicas
}

\author{
José María Oliva iD \\ Editor de la revista.josemaria.oliva@uca.es
}

Monographs and special issues in scientific journals

Para citar este artículo: Oliva J. M. (2021) Monográficos y números especiales en revistas científicas. Revista Eureka sobre Enseñanza y Divulgación de las Ciencias 18(1), 1001. doi: 10.25267/Rev_Eureka_ensen_divulg_cienc.2021.v18.i1.1001

La edición de monográficos que aglutinen trabajos sobre un tema concreto es una práctica habitual de muchas revistas académicas, que sirve para mejorar el estado del arte sobre los campos de conocimientos implicados y ayuda, además, a dar un impulso a determinadas líneas que se consideran relevantes en un momento dado. Partimos de esta base, y de que la inclusión de monográficos en las revistas supone una práctica saludable y una prueba de madurez de las publicaciones que lo hacen.

Sin embargo, consideramos que el proceso natural para la publicación de esos monográficos no debería ser el de la edición de números especiales, sino el de su incorporación en números ordinarios de la revista. En este sentido, conviene tener en cuenta que el ISSN que tiene asignado cualquier revista, tramitado a través del Ministerio de Cultura, está asociado a una serie de características y parámetros que, en principio, deberían ser invariables, como el título de la publicación, la periodicidad con que se publica, etc. Por ello, no resulta conveniente la inclusión de números extraordinarios, los cuales, en cierto modo, se entienden que son anexos o complementos de la revista, pero no parte orgánica de la misma.

De este modo, bases de datos como Web of Science o Scopus, son reacias a indexar los artículos de esos números especiales, y de hecho no lo hacen. Esto tiene repercusiones también en la valoración de los méritos de investigación de los autores de artículos publicados en estos números, ya que tales artículos no heredan los criterios de calidad y excelencia de la revista en que se publican. Por ejemplo, un artículo de un número especial de una revista indexada en Scopus, no hereda la condición de publicación de impacto, pues dicho artículo no queda indexado en la base de datos y, por consiguiente, no contribuye al factor de impacto de la revista.

Sensibles a esta situación, y con el convencimiento de la utilidad de los títulos monográficos por las razones antes señaladas, REurEDC abre la posibilidad de incluir secciones monográficas especiales, como es el caso de la que se publica este año 2021 sobre investigaciones basadas en el diseño de secuencias de enseñanza-aprendizaje. En concreto, bajo el título de "Investigaciones de diseño", en este primer número del año se incluyen tres artículos para dicha sección. Sirva este editorial, junto el que publicamos hace unos meses (Guisasola y Oliva 2020), como nuevo llamamiento para artículos con este perfil.

\section{Referencias}

Guisasola J. y Oliva J.M. (2020) Nueva sección especial de REurEDC sobre investigación basada en el diseño de secuencias de enseñanza-aprendizaje. Revista Eureka sobre Enseñanza y Divulgación de las Ciencias 17(3), 3001. https://doi.org/10.25267/Rev_Eureka_ensen_divulg_cienc.2020.v17.i3.3001 